\title{
MENINGKATKAN KAPASITAS LOADING MESIN PRESS 1000T PADA PROSES PRESS BRACKET SUPPORT AIR TANK DENGAN METODE PDCA DI PT. XYZ
}

\author{
Renty Anugerah Mahaji Puteri ${ }^{1 *}$, Mohamad Sahrul Ramadhon ${ }^{2}$ \\ ${ }^{1,2}$ Jurusan Teknik Industri, Fakultas Teknik, Universitas Muhammadiyah Jakarta \\ J1. Cempaka Putih Tengah 27 Jakarta 10510 \\ *Email: renty.puteri@gmail.com
}

Diterima: 29 Juli 2015 Direvisi: 10 September $2015 \quad$ Disetujui: 23 Oktober 2015

\begin{abstract}
ABSTRAK
Agar proses produksi bisa berjalan dengan lancar, diperlukan improvement. Dalam pembahasan ini, improvement yang akan dilakukan terkait dengan proses pembentukan part bracket support air tank. Adapun metode yang digunakan pada penelitian ini adalah PDCA (Plan Do Check Action). Metode ini diangkat penulis sebagai metode yang paling cocok untuk diterapkan pada perusahaan yang bergerak di bidang otomotif seperti PT. XYZ ini. Yang menjadi titik fokus dari improvement yang akan dilakukan saat ini adalah dies untuk part bracket support air tank. Produk ini dianggap cocok untuk menjadi bahan improvement karena merupakan new project. Sehingga dapat melakukan improvement yang ekstrim sekalipun tanpa harus mengganggu produksi yang sedang berlangsung. Untuk itu penyesuaian atau rekayasa terhadap dies dari part tersebut akan dilaksanakan guna mencapai hasil atau target yang diinginkan.Adapun hasil yang diharapkan dari penelitian ini adalah tercukupinya kapasitas mesin untuk melakukan proses - proses yang harus dilakukan untuk pembuatan part bracket support air tank. Selain itu, kualitas dari produk yang dibuat juga menjadi item yang harus tetap dijaga. Karena kualitas dari produk yang dibuat akan menjaga kepercayaan customer terhadap PT. $X Y Z$.
\end{abstract}

Kata kunci: Dies, Loading, PDCA, Improvement.

\begin{abstract}
The improvement is need to support production process run smoothly. In this research, improvement which will be associated with the formation of the support bracket part water tank. The method used in this study is the PDCA (Plan Do Check Action). This method was appointed the author as the most suitable method to be applied to companies engaged in the automotive field, such as PT. This XYZ. Which became the focal point of improvement to be done now is to spare dies bracket support the water tank. This product is considered suitable to be a material improvement because it is a new project. So that it can perform extreme improvement even without having to disrupt the ongoing production. For the adjustment or the engineering of the dies of the part to be implemented in order to achieve the target. The aim oh this research are inadequate capacity of the machine to perform a process - a process that must be done for the manufacture of spare water tank support bracket. In addition, the quality of products made also be items that must be kept. Due to the quality of the products made will maintain the confidence of customers to PT. XYZ.
\end{abstract}

Keywords : Dies,Loading,PDCA,Improvement. 


\section{PENDAHULUAN}

PT. XYZ adalah salah satu anak perusahaan yang bergerak dibidang Frame chasis assy dan stamping under body part.Frame chassis yang merupakan salah satu komponen utama pada kendaraan roda empat yang berfungsi sebagai penahan beban pada komponen kendaraan dan penahan suspensi ketika terjadi beban saat bergerak. Produk utama PT. XYZ adalah frame chassis Kategori II (Medium sizedtruck), dan Kategori III (Heavy duty truck) crossmember dan komponen - komponen under body lainnya.

Salah satu costumer utama dari PT. XYZ adalah PT. Hino Motor Manufacturing Indonesia. Selain part - part reguler, PT. Hino juga memberikan part - part baru (New Project) untuk menggantikan part yang lama. Adapun waktu development part - part baru tersebut, diperlukan waktu trial yang tidak sebentar. Hal inilah yang menjadikan loading capacity dari mesin produksi tersebut menjadi issue yang penting. kapasitas produksi dari suatu mesin sendiri tergantung pada banyaknya proses yang dikerjakan, kecepatan memproses suatu part, waktu persiapan (Set-up Time), waktu tidak beroperasi (Down Time). Loading mesin yang melebihi kapasitas dapat mengakibatkan beberapa masalah, seperti tidak terpenuhinya volume produksi, delivery part menjadi terlambat atau bahkan tidak dapat mengirim part ke costumer. Dan pada akhirnya hilangnya kepercayaan costumer ke kita (PT. GKD). Untuk hal tersebut, perlu dilakukan bberapa tindakan guna menghilangkan masalah-masalah tersebut, seperti mempekerjakan karyawan melebihi waktu normal (lembur/ over time), menambah kapasitas dengan membeli mesin baru, transfer loading part kemesin lain atau bahkan transfer ke supplier (vendor to vendor). Akan tetapi beberapa penyelesaian diatas memerlukan waktu dan effort yang tidak mudah. Seperti menambah mesin baru, penyelesaian ini memerlukan dana yang tidak sedikit dan waktu yang cukup lama. Kemudian transfer loading, hal ini perlu adanya persetujuan oleh customer. Karena ditakutkan akan terjadi penuruna kualitas yang dapat menggangu produksi. Hal yang aling mudah adalah lembur, akan tetapi dimasa yang sulit seperti saat ini lembur dianggap sebagai pilihan kedua. Karena biaya yang dikeluarkan akan lebih tinggi dari pada produksi dihari normal. Oleh karena itu proses improvement harus dilakukan agar perusahaan dapat bertahan dimasa - masa sulit ini.

Banyak cara untuk meningkatkan kapasitas mesin, salah satu-nya adalah menggabung 2 proses atau lebih menjadi 1 proses sehingga proses pengerjaan dapat hilang hingga 50\% (asumsi menghilangkan salah satu waktu proses). Jika dilakukan perhitungan sederhana untuk penentuan LVC mesin press, maka perhitungannya seperti berikut: Produksi part bracket air tank selama sebulan adalah 1248 Unit/ bulan atau 2496 pcs/ bulan (quantity kebutuhan part didapat dari RFQ customer). Berdasarkan data tersebut, maka dibutuhkan waktu sekitar 57 Jam kerja per bulan. Jika ditambahkan pada loading mesin press $1000 \mathrm{~T}$ dengan kebutuhannya selama 3 bulan berturut - turut yaitu : 488,66 jam pada bulan Oktober 2014, 434,70 jam pada bulan November 2014 dan 428,43 jam pada bulan Desember 2014. Sedangkan kapasitas tiap bulannya adalah 426 jam pada bulan Oktober 2014, 371 jam pada bulan November 2014 dan 371 jam pada bulan Desember 2014. Maka dibutuhkan waktu lembur untuk tiap bulan berturut - turut adalah 62,59 jam dibulan Oktober 2014, 64,20 jam pada bulan November 2014 dan 57,93 jam pada bulan Desember 2014. Untuk itu perlu dilakukan improvement agar dapat meningkatkan proses produksi dari suatu mesin. Sehingga kapasitas produksi PT. XYZ pun akan ikut meningkat.

Dalam improvement kali ini, yang akan dilakukan adalah modifikasi tooling (dalam pembahasan kali ini dies) sehingga dapat menghilangkan perbedaan parameter yang ada, yang bertujuan untuk menggabungkan 2 proses menjadi 1. Adapun part yang akan menjadi subjek improvement adalah bracket support air tank. Part ini diambil karena new project bagi PT. XYZ yang sangat penting demi kelangsungan bisnis. Selain itu, setiap kali naik produksi, part ini memeliki reject ratio yang tinggi. Hal ini juga menjadi faktor bertambahnya waktu produksi. Oleh masalah - masalah yang telah disampaikan diatas, perlu segera dilakukan imrovement dengan tujuan meningkatkan kapasitas produksi mesin.

\section{METODE}

Langkah awal untuk meningkatkan kapasitas produksi mesin press 1000 Ton adalah dengan mengidentifikasikan part - part 
dan proses apa saja yang diproses pada mesin tersebut (observasi lapangan). Setelah didapat part dan proses yang sesuai dengan tema improvement, langkah berikutnya adalah mengumpulkan data - data mengenai part tersebut. Baik dari segi dimensi part, parameter poses, spesifikasi mesin, spesifikasi tooling part dan data lain yang dapat digunakan untuk menunjang improvement. Data - data tersebut kemudian diolah sehingga dapat lebih mudah untuk dipahami oleh orang. Lalu data yang sudah diolah kemudian dianalisa sehingga didapat pemecahan masalah sehingga improvement dapat dilakukan dan hasil sesuai dengan target.

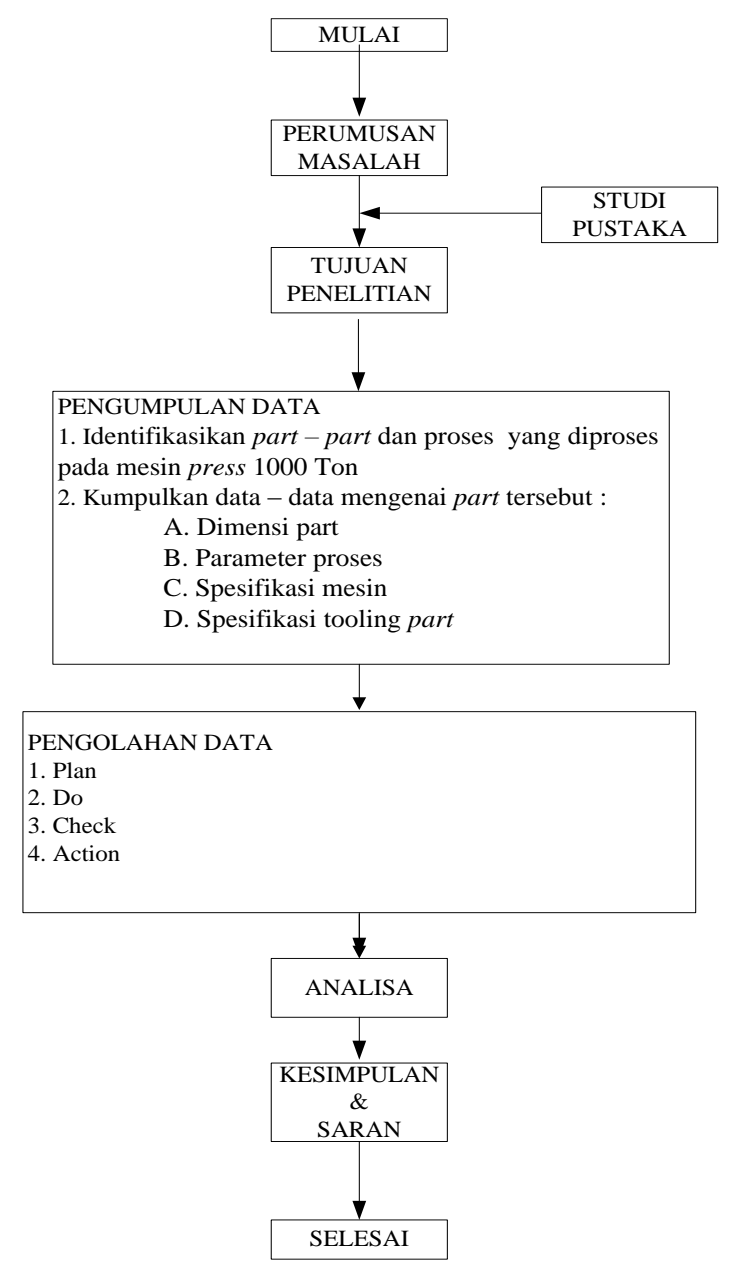

Gambar 1. Bagan Alir Penelitian

\section{HASIL DAN PEMBAHASAN}

\section{Plan}

Semua masalah pasti ada penyebab yang mengakibatkan masalah tersebut terjadi. Pada kesempatan kali ini penulis akan menganalisa terjadinya masalah yang terbesar / paling tinggi rasionya dibandingkan masalah lainnya.
Adapun tool yang akan digunakan untuk menganalisa adalah tabel "why - why analisys". Berikut adalah diagramnya :

Tabel 1 . Tabel why - why analisys problem hole mepet

\begin{tabular}{|c|c|c|c|c|c|}
\hline $4 \mathrm{M}-1 \mathrm{E}$ & $1^{\text {st }}$ WHY & $2^{\text {nd }} W H Y$ & $3^{\text {rd }}$ WHY & $4^{\text {th }}$ WHY & $\begin{array}{l}5^{\text {th }} \\
\text { WHY }\end{array}$ \\
\hline \multirow[b]{2}{*}{ MAN } & $\begin{array}{l}\text { Panjang } \\
\text { part minus }\end{array}$ & $\begin{array}{l}\text { Penempatan } \\
\text { part tidak } \\
\text { sempurna } \\
\text { (part berada } \\
\text { diatas } \\
\text { stopper) }\end{array}$ & $\begin{array}{l}\text { Panjang } \\
\text { part } \\
\text { perform } \\
(350) \text { over }\end{array}$ & $\begin{array}{l}\text { Stoper proses } \\
\text { perform } \\
\text { bergeser }\end{array}$ & $\begin{array}{l}\text { Stoper } \\
\text { belum } \\
\text { didowel }\end{array}$ \\
\hline & $\begin{array}{l}\text { Panjang } \\
\text { part minus }\end{array}$ & $\begin{array}{l}\text { Penempatan } \\
\text { part tidak } \\
\text { sempurna } \\
\text { (part berada } \\
\text { diatas } \\
\text { stopper) }\end{array}$ & $\begin{array}{l}\text { Bentukkan } \\
\text { profil } \\
\text { perform } \\
\text { tidak sama } \\
\text { dengan } \\
\text { profil dies } \\
\text { forming } \\
\end{array}$ & - & - \\
\hline \multirow[b]{2}{*}{ METHOD } & $\begin{array}{l}\text { Panjang } \\
\text { part minus }\end{array}$ & $\begin{array}{l}\text { Stopper jarak } \\
350 \text { bergeser }\end{array}$ & $\begin{array}{l}\text { Stopper } \\
\text { terdorong } \\
\text { material }\end{array}$ & $\begin{array}{l}\text { Stoper } \\
\text { kurang rigid }\end{array}$ & - \\
\hline & $\begin{array}{l}\text { Panjang } \\
\text { part minus }\end{array}$ & $\begin{array}{l}\text { Stopper jarak } \\
350 \text { bergeser }\end{array}$ & $\begin{array}{l}\text { Stopper } \\
\text { terdorong } \\
\text { material }\end{array}$ & $\begin{array}{l}\text { Stoper area } \\
\text { flange } \\
\text { menghalangi } \\
\text { pergerakan } \\
\text { material saat } \\
\text { proses } \\
\text { stamping } \\
\end{array}$ & - \\
\hline MATERIAL & - & - & - & - & - \\
\hline \begin{tabular}{|l|} 
MACHINE \\
\end{tabular} & - & - & - & - & - \\
\hline $\begin{array}{c}\text { NVIRONME } \\
\text { NT }\end{array}$ & - & - & - & - & - \\
\hline
\end{tabular}

(Sumber : Data observasi lapangan)

Do

\section{Perhitungan tonase / gaya kerja per proses \\ a. Proses preform}

Untuk mengetahui besarnya gaya yang diperlukan, kita akan menggunakan rumus sebagai berikut :

$$
P b u=\frac{k \cdot s \cdot \sigma \cdot b \cdot t \cdot w}{1000}=\frac{0,3 \cdot 45 \cdot 4,5 \cdot 116}{1000}=6,89 \text { ton }
$$

Data tonase tersebut merupakan gaya yang diperlukan tanpa ada daya penahan dari pad. Apabila ped bekerja sebagaimana fungsinya, maka rumus yang berlaku menjadi seperti berikut :

$$
\mathrm{P}^{\prime} \mathrm{bu}=\mathrm{Pbu}+\mathrm{Pbp}=6,89+1,8=8,72 \text { ton }
$$

Maka gaya yang dibutuhkan untuk melakukan proses preform adalah sebesar 8,72 Ton.

\section{b. Proses forming}

Seperti pada halnya perhitungan pada proses preform, perhitungan gaya yang diperlukan untuk proses forming adalah sebagai berikut: 


$$
P b u=\frac{k \cdot s \cdot \sigma \cdot b \cdot t \cdot w}{1000}=\frac{0,3 \cdot 45 \cdot 4,5 \cdot 1939,77}{1000}=117,84 \text { ton }
$$

Data tonase tersebut merupakan gaya yang diperlukan tanpa ada daya penahan dari pad.

Maka gaya yang dibutuhkan untuk melakukan proses forming adalah sebesar $\mathbf{1 1 9 , 8 7}$ Ton

Dari 2 perhitungan gaya diatas, maka didapat hasil besaran gaya yang diperlukan apabila proses forming dan proses preform digabungkan menjadi satu adalah sebesar 128,59 Ton. Apabila kedua proses tersebut dijalankan pada mesin 1000T, maka secara hitungan tonase tidak mengalami kendala.

\section{c. Pembuatan design holder}

Agar kedua proses tersebut dapat dilakukan pada waktu yang sama dan mesin yang sama, untuk itu diperlukan adanya tambahan base atau holder. Adapun fungsi dari holder tersebut adalah membuat DH (Die Height) kedua dies tersebut sama. Oleh sebab itu dibuatkanlah sebuah holder dengan didasari perbedaan tinggi kedua dies itu. Adapun design holder itu adalah sebagai berikut :

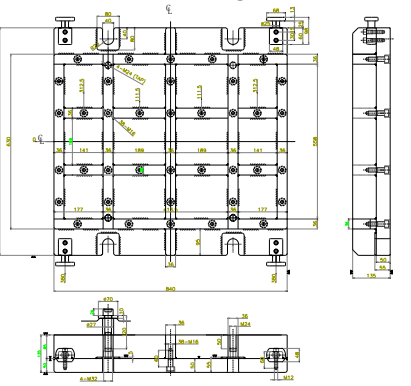

Gambar 2. Design holder untuk dies pre-form

\section{Check}

Selain itu, ada juga efek quality yang ditimbulkan karena perbaikan ini, yaitu tinggi part menjadi lebih stabil. Selama pada tanggal 20 Januari 2015 sampai dengan akhir Januari telah diproduksi part bracket air tank sebanyak 439 pcs, dan part yang reject ada 11 pcs. Artinya prosentase reject turun dari $10,2 \%$ menjadi $2,5 \%$.

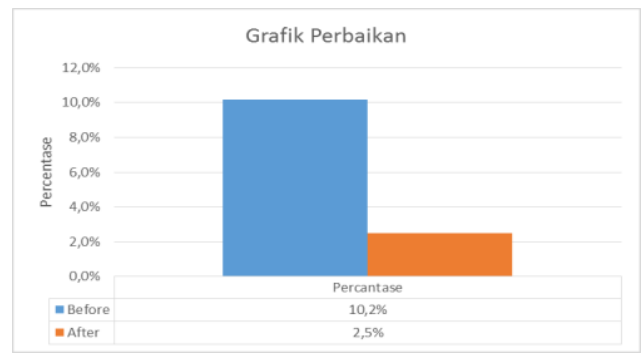

Gambar 3. Grafik penurunan reject

\section{Action}

Agar improvement yang dilakukan ini menjad proses yang standard, maka untuk itu diperlukan perubahan dokumen - dokumen kerja yang terkait. Dalam hal ini dokumen yang dimaksud adalah DSS (Die Steeing Standard). yang mana dokumen ini berfungsi untuk menetapkan parameter dalam proses stamping. Adapun yang tertulis dalam dokumen ini adalah parameter mesin. Setelah dilakukan beberapa penyesuaian pada dies, didapatlah parameter mesin sebagai berikut :

Tabel 2. Tabel Parameter Mesin Sesudah Penyesuaian

\begin{tabular}{|c|c|c|}
\hline No & Item (preform) & $\begin{array}{c}\text { Parameter } \\
\text { Preform \& } \\
\text { Forming }\end{array}$ \\
\hline 1 & Shut Height & $913 \mathrm{~mm}$ \\
\hline 2 & Cushion Pin & $575 \mathrm{~mm}$ \\
\hline 3 & Qty Cushion Oin & $3 \mathrm{pcs}$ \\
\hline 4 & Die Cushion Height & $420 \mathrm{~mm}$ \\
\hline 5 & Speed per Minute & 15 \\
\hline 6 & Air Pressure & $1,0 \mathrm{kgf} / \mathrm{cm}^{2}$ \\
\hline
\end{tabular}

\section{Analisa Kapasitas Produksi}

Data kapasitas mesin press 1000T yang dijadikan sebagai bahan penelitian ini selama periode bulan Oktober - November Desember 2014. Pada jangka waktu tersebut, kapasitas produksi mesin press 1000T sudah melebihi dari 3 shift produksi. Sehingga membutuhkan waktu tambahan atau lembur agar target produksi dapat tercapai. Hal ini dapat terlihat pada grafik 4.1 (LVC mesin B6) dan grafik 4.2 (LVC mesin B7), kedua grafik tersebut menunjukan bahwa loading produksi mengharuskan pekerja masuk pada hari sabtu agar target tercapai.

Setelah dilakukan improvement penggabungan proses preform dan forming menjadi satu, terdapat penurunan loading untuk mesin press B6. Meskipun penurunan 
tidak terlalu signifikan, tetapi proses improvement membuat tidak diperlukannya lagi waktu lembur untuk mencapai target. Hal ini terlihat pada grafik dibawah ini :

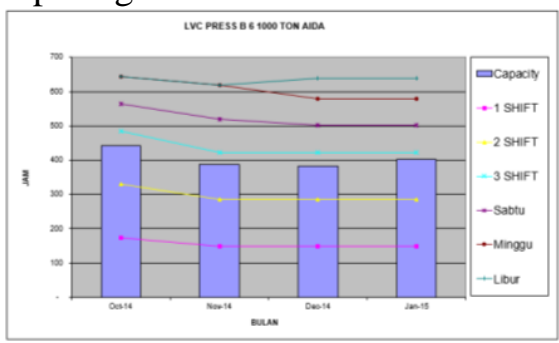

Gambar 4. Grafik LVC mesin B6

Dari Grafik diatas, dapat dilihat bahwa loading produksi sudah berada dibawah 3 shift. Sehingga tidak diperlukan lagi lembur untuk mencapai target produksi. Sehingga target dari improvement ini pun tercapai, yaitu menurunkan loading mesin press 1000T dibawah 3 shift.

\section{Analisa Terhadap Reject Part}

Berdasarkan grafik 4.6 didapat bahwa jenis reject lubang mepet adalah yang tertinggi dengan total part 213 pcs atau sekitar $10,2 \%$ dari total produksi selama periode Januari 2015. Yang menjadi penyebab dari reject ini adalah kurang stabilnya proses preform sehingga mengakibatkan perubahan profil bending. Hal ini mengakibatkan perubahan peletakan material terhadap stopper proses forming. Untuk detail analisa penyebab reject dapat dilihat pada tabel 4.4 (tabel why - why analisys). Untuk mengatasi masalah ini adalah perlu dilakukan suatu kegiatan improvement untuk menstabilkan profil preform. Dan salah satu yang dapat dilakukan adalah dengan menggabungkan proses preform dan forming menjadi satu.

Setelah improvement dilakukan, terdapat perbaikan untuk problem reject ini. Terjadi penurunan persentase reject lubang mepet. Dari $10,2 \%$ menjadi hanya $2,5 \%$. Perbaikan ini dapat terlihat pada grafik 4.7. (grafik penurunan reject).sehingga terjadi pergeseran pareto masalah. Dan masalah ini dapat diperbaiki pada kegiatan improvement selanjutnya. Karena kegiatan perbaikan harus tetap berjalan untuk mencapai produksi yang efektif.

\section{Analisa Terhadap Improvement Dies}

Analisis improvement dies yang telah dilakukan pada pembahasan kali ini adalah sebagai berikut :

Men-design holder untuk dies preform dengan maksud menyamakan tinggi dies preform dengan dies forming. Langkah ini dilakukan agar penggabungan proses preform dan forming dapat dilakukan. Karena terdapat perbedaan tinggi dies yang signifikan $(132,7 \mathrm{~mm})$. Sehingga dibutuhkanlah holder tambahan untuk mengatasi perbedaan tinggi tersebut. Berikut adalah tampilan dies preform yang sudah diberikan holder tambahan :

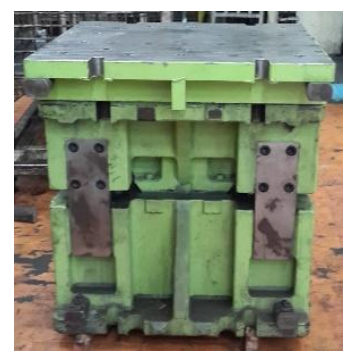

Gambar 5. Dies prefrom dengan holder tambahan

Setelah dies preform ditambahkan dengan holder, kemudian dilakukan trial peletakan dies diatas mesin. Hal ini dilakukan agar jika terdapat kekurangan dari design ataupun dari hal lainnya dapat langsung terlihat. Berikut adalah tampilan dies preform dan formning diatas mesin secara bersamaan :

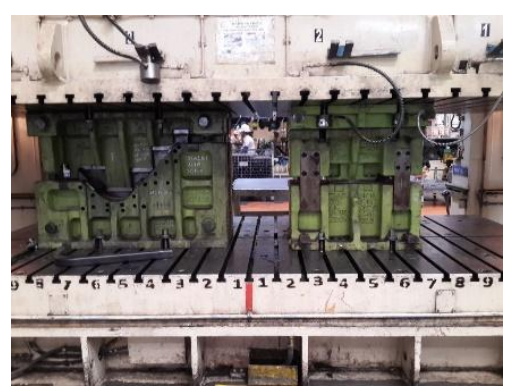

Gambar 6. Foto dies preform dan forming diatas mesin

Dari trial tersebut, tidak terdapat keabnormalan yang berpengaruh pada proses produksi. Melakukan perhitungan gaya, agar dapat mengetahui kelayakan improvementyang akan dilakukan. Perhitungan ini dilakukan agar dapat mengetahui kemampuan press dari mesin untuk melakukan kedua proses trersebut dalam waktu yang bersamaan. Karena jika 
kemampuan atau kapasitas mesin dibawah gaya yang dibutuhkan untuk melakukan press, maka akan terjadi overload dan berpotensi merusak mesin. Setelah dilakukan perhitungan pada bab sebelumnya, didapat hasil tonase yang dibutuhkan untuk melakukan proses produksi jauh dibawah kapasitas mesin. Dan dapat diambil kesimpulan, penggabungan kedua proses ini bisa dilakukan dimesin press 1000T.

Penggantian standard parameter proses untuk mesin press $1000 \mathrm{~T}$ B6 dan B7. Hal ini dilakukan agar standarisasi yang telah dibuat pada saat trial dapat tetap terjaga hingga saat produksi. Standard tersebut tertulis kedalam form DSS (Dies Setting Standard). DSS berisikan standard - standard penyettingan dies terhadap mesin. Parameter yang tertulis di DSS anatara lain : Die Height, Air Pressure, Cushion Height, Qty Cushion, Air Balancer, DLL. Semua parameter tersebut berfungsi untuk menjaga quality dari produk saat proses berlangsung.

\section{KESIMPULAN DAN SARAN}

Setelah dijalankannya improvement ini, maka didapatkan hasil yang positif. Adapun kesimpulan dari improvement ini adalah sebagaiberikut :

1. Meningkatnya kapasitas produksi mesin 1000T. Sehingga proses produksi part bracket air tank capable untuk dijalankan.

2. Menghilangkan lembur untuk mencapai target produksi. Dengan menurunnya loading mesin press 1000T menjadi dibawah 3 shift produksi, sehingga tidak diperlukan lembur untuk mencapai target. Dengan catatan, semua proses yang berjalan pada mesin tersebut berjalan dengan normal dan juga tidak ada penambahan loading pada mesin tersebut.

3. Menurunkan persentase reject. Efek yang ditimbulkan dari improvement ini dari segi kualitas yaitu, penurunan reject ratio untuk problem lubang mepet. Dari total produksi dari tanggal 20 Januari 2015 part bracket air tank sebanyak 439 pcs, dan part yang reject ada 11 pcs. Artinya prosentase reject turun dari $10,2 \%$ menjadi $2,5 \%$.

Saran yang dapat diberikan kepada PT. XYZ adalah bahwa perusahaan wajib melakukan continous improvement dalam menjaga kualitas dan eksistensi perusahaan.

\section{DAFTAR PUSTAKA}

Indri Parwati, Cyrilla. Pengendalian Kualitas Produk Cacat Dengan Pendekatan Kaizen Dan Analisis Masalah Dengan Seven Tools. Yogyakarta.

Ivanto, Muhammad.,Pengendalian Kualitas Produksi Koran Menggunakan Seven Tools Pada PT. Akcaya Pariwara Kabupaten Kubu Raya. Sumatera Utara.

Kastono, Andri. 2014,Pengendalian Kualitas Dalam Upaya Menurunkan Cacat Appearance Dengan Metode PDCA. Jakarta.

Natasya, Meirilyn.2012, Implementasi Pengendalian Dengan Menggunakan Metode Statistik Pada PT. Industri Marmer Indonesia Tulungagung. Surabaya.

Press Die Component Team.2007 Misumi Press Die Standard Part Technical Specification. $1^{\text {st }}$ Edition, Misumi Corporation.

Santosa Putra, Yoan.,Pengaruh Kualitas Pelayanan Terhadap Kepuasan Pelanggan Pengguna Jasa Parkir. Malang

Sudarmadji, Hery.2011,Aplikasi Metoda SMED Untuk Perbaikan Proses Ganti Model (Change Overtime) Dan Waktu Penyetelan (Set-up Time). Bandung.

Sudarmawan, Rony.2009,Teknologi Press Dies Panduan Design, Penerbit Kanisius.

Yessicha, Marissa.2011,Upaya Minimalisasi Kekurangan Material Melalui Implementasi Quality Control Circle. Surabaya. 